\title{
Kombinasi Simple Multy Attribute Rating (SMART) dan Technique for Order Preference by Similarity to Ideal Solution (TOPSIS) dalam Menentukan Kualitas Varietas Padi
}

\author{
Fatma Sari Hutagalun, Herman Mawengkang, Syahril Efendi \\ Program Studi Magister Teknik Informatika, Fakultas Ilmu Komputer dan Teknologi Informasi, Medan, Universitas Sumatera Utara
}

\begin{tabular}{l} 
KEYWORDS \\
\hline Sistem Pengambil Keputusan, SMART, \\
TOPSIS, Varietas Padi \\
CORRESPONDENCE \\
\hline Phone: \\
E-mail:
\end{tabular}

\section{PENDAHULUAN}

\section{Latar Belakang}

Padi dibudidayakan dengan tujuan untuk mendapatkan hasil dan kualitas sebaik mungkin. Di Indonesia dikenal lebih dari 1.000 jenis benih padi (varietas), jumlah yang banyak itu memungkinkan petani kesulitan dalam memutuskan benih mana yang berkualitas yang akan mereka tanam. Kesalahan dalam memilih jenis varietas padi akan mengakibatkan hasil yang tidak sesuai, bahkan gagal panen. Dalam menentukan kualitas padi diperlukan beberapa kriteria yang mempengaruhi kualitas varietas padi, yaitu umur tanaman, tinggi tanaman, kerontokan, rata-rata hasil dan potensi hasil.

Sistem Pendukung Keputusan (SPK) sangat tepat diterapkan dalam proses pemberian solusi dalam suatu permasalahan dalam banyak kriteria atau Multicriteria Decision Making (MDM) (Scott el al., 2014). Dalam SPK, solusi yang ditampilkan berupa bentuk peringkat. Banyak metode yang dapat digunakan untuk untuk menyelesaikan masalah multicriteria misalnya metode WP (Weight Product) metode WP merupakan salah satu metode penyelesaian multicriteria, dalam perhitungan WP tidak diperlukan normalisasi sehingga waktu yang diperlukan juga lebih singkat. Dalam menentukan kuliatas varietas padi adalah dengan menetapkan keputusan multi kriteria yang didasarkan pada teori bahwa setiap alternatif terdiri dari beberapa kriteria yang memiliki nilai-nilai, dan setiap kriteria memiliki bobot yang menggambarkan seberapa penting kriteria tersebut dibandingkan dengan kriteria yang lain. Pembobotan ini digunakan untuk menilai setiap alternatif agar diperoleh alternatif terbaik.

Metode solusi masalah multikriteria menggunakan metode SMART memiliki kelebihan antara lain dapat melakukan penambahan atau pengurangan alternatif, sehingga setiap penambahan alternatif atau varietas padi tidak akan mempengaruhi perhitungan pembobotan, karena setiap penilaian alternatif tidak saling bergantung. Kelebihan lain nya adalah perhitungan SMART sangat sederhana sehingga tidak memerlukan perhitungan matematis yang rumit yang memerlukan pemahaman matematika yang kuat (Freerk A. Lootsma). Metode SPK yang lain yang dibahas dalam penelitian ini yaitu metode Technique for Order Preference by Similarity to Ideal Solution (TOPSIS). Metode ini dinilai lebih realistis dibanding metode 
yang lain karena hasil yang buruk pada sebuah kriteria dapat diimbangi oleh hasil yang baik pada kriteria lain (Greene at al., 2011). Penelitian ini mencoba mengkombinasikan kedua metode SPK yakni metode SMART dan TOPSIS. Penggabungan kedua metode ini diharapkan mampu menentukan kualitas varietas padi berdasarkan beberapa kriteria yang telah ditentukan. Penelitian ini dilakukan dengan mencari nilai normalisasi matriks untuk setiap atribut menggunakan metode SMART kemudian dilanjutkan dengan metode TOPSIS untuk mencari alternatief atau solusi yang dipilih.

\section{Rumusan Masalah}

Berdasarkan latar belakang masalah diatas, maka rumusan masalah dalam penelitian ini adalah : Bagaimana menggabungkan metode SMART dan TOPSIS dalam mementukan kualitas varietas padi?

\section{Batasan Masalah} berikut :

Adapun batasan masalah dalam penelitian ini adalah sebagai

1. Penelitian menggunakan metode Simple Multy Attribute Rating (SMART) dan TOPSIS

2. Metode $S M A R T$ digunakan untuk menghitung nilai normalisasi matriks, dan metode TOPSIS digunakan untuk mencari solusi untuk setiap alternatif

3. Kriteria yang digunakan dalam penelitian adalah: umur tanaman, tinggi tanaman, kerontokan, rata-rata hasil, dan potensi hasil

4. Analisis akan menghasilkan keputusan kualitas varietas padi super, premium, medium, redah

5. Penelitian menggunakan 18 jenis varietas padi

\section{Tujuan Penelitian}

1. Menganalisis kombinasi Simple Multy Attribute Rating (SMART) dan TOPSIS dalam menentukan kualitas varietas padi untuk memudahkan petani dalam mengambil keputusan.

2. Memudahkan petani dalam memilih verietas padi yang berkualitas untuk ditanam.

\section{TINJAUAN PUSTAKA}

\section{Perbandingan Penelitian sebelumnya dengan penelitian yang dilakukan}

Muhammad rendara husein, (2017) melakukan penelitian menggunakan metode AHP dan TOPSIS untuk menentukan pemilihan penananaman varietas padi. Penelitian ini menghasilkan, (1) Akurasi kecocokan antara hasil keluaran sistem dengan hasil keluaran ahli dibidang pertanian khususnya penelitian varietas padi sebesar $83.33 \%$. (2) Pemilihan varietas aletrnatif dilakukan dengan memperhitungkan peringkat alternatif yang disesuaikan dengan kemampuan serta kebutuhan pengambil keputusan. Dalam penelitian ini ada beberapa kekurang antara lain, kriteria yang digunakan dalam penelitian ini belum cukup maksimal untuk dijadikan kriteria dalam pengambilan keputusan. Ita Rofiqoh, melakukan penelitian untuk mendukung keputusan dalam pemilihan penanaman varietas padi unggul padi mengguakan metode TOPSIS. Penelitian ini menghasilkan, dalam mendukung keputusan untuk memilih bibit unggul padi yang tepat, metode Technique for Order Preference by Similarity to Ideal Solution (TOPSIS) dapat diterapkan dengan baik serta mampu menunjukkan salah satu alternatif input merupakan prioritas dari keputusan.

\section{SMART (Simple Multi Attribute Rating Technique)}

SMART ( Simple Multi Attribute Rating Technique ) merupakan metode pengambilan keputusan yang multiatribut yang dikembangkan oleh Edward pada tahun 1977. Teknik pembuatan keputusan multiatribut ini digunakan untuk mendukung pembuat keputusan dalam memilih antara beberapa alternatif. Setiap pembuat keputusan harus memilih sebuah alternatif yang sesuai dengan tujuan yang telah dirumuskan. Setiap alternatif terdiri dari sekumpulan atribut dan setiap atribut mempunyai nilai-nilai. Nilai ini diratarata dengan skala tertentu. Setiap atribut mempunyai bobot yang menggambarkan seberapa penting dibandingkan dengan atribut lain.

Pembobotan dan pemberian peringkat ini digunakan untuk menilai setiap alternatif agar memperoleh alternatif terbaik. Pembobotan pada SMART ( Simple Multi Attribute Rating Technique ) menggunakan skala antara 0 - 100, agar mempermudah perhitungan dan perbandingan nilai pada masing-masing alternatif.

Model yang digunakan dalam SMART (Simple Multi Attribute Rating Technique) yaitu :

$u\left(a_{i}\right)=\sum_{j_{m 1}}^{m} w_{j} u_{i} i\left(a_{i}\right) \quad i=1,2 \ldots . m$

Keterangan:

$w_{j} \quad=$ nilai pembobotan kriteria ke-j dan $k$ kriteria $u\left(a_{i}\right)=$ nilai utility kriteria ke-i untuk kriteria ke-i

Pemilihan keputusan adalah mengidentifikasi mana dari $\mathrm{n}$ alternatif yang mempunyai nilai fungsi terbesar.

Teknik Motode SMART (Kustiyahningsih, Anamisa dan Syafa'ah, 2013)

1. Langkah 1: menentukan jumlah kriteria

2. Langkah 2: sistem secara default memberikan skala 0-100 berdasarkan prioritas yang telah diinputkan kemudian dilakukan normalisasi.

Normalisasi $=\frac{w_{j}}{\sum \boldsymbol{w}_{j}}$

Dimana wj : bobot suatu kriteria

Langkah 3: memberikan nilai kriteria untuk setiap alternatif.

Langkah 4: hitung nilai utility untuk setiap kriteria masingmasing.

$$
\boldsymbol{u}_{i}\left(\boldsymbol{a}_{i}\right)=100 \frac{\left(\boldsymbol{C}_{\max }-\boldsymbol{C}_{\text {out } i}\right)}{\left(\boldsymbol{C}_{\max }-\boldsymbol{C}_{\min }\right)} \%
$$

Dimana :

ui(ai) : nilai utility kriteria ke-1 untuk kriteria ke-i

Cmax : nilai kriteria maksimal

Cmin : nilai kriteria minimal

Cout i : nilai kriteria ke-i 


\section{Technique For Order Preference by Similarity to Ideal Solution (TOPSIS)}

TOPSIS adalah kategori MultiCriteria Decision Making (MCDM) yaitu teknik pengambilan keputusan dari beberapa pilihan alternatif yang ada, khususnya MADC.(Multi Attribute Decision Making). Menurut Hwang ( Sri Kusumadewi, 2006, h.87), menyatakan bahwa : " Topsis menggunakan prinsip bahwa alternatif yang terpilih harus mempunyai jarak terdekat dari solusi ideal positif dan jarak terpanjang (terjauh) dari solusi ideal negatif dari sudut pandang geometris dengan menggunakan jarak Eucliden (jarak antara dua titik) untuk menentukan kedekatan relatif dari suatu alternatif dengan solusi optimal. Solusion ideal positif didefenisikan sebagai jumlah dari seluruh nilai terbaik yang dapat dicapai untuk setiap atribut, sedangkan solusi negatif-ideal terdiri dari seluruh nilai terburuk yang dicapai untuk setiap atribut. TOPSIS mempertimbangkan keduanya, jarak terhadap solusi ideal negatif dengan mengambil kedekatan relative terhadap solusi ideal positif.

\section{Langkah-langkah Metode TOPSIS}

Langkah-langkah yang dilakukan dalam menyelesaikan suatu permasalahan menggunakan metode TOPSIS adalah sebagai berikut (Sri Kusumadewi, 2006) :

\section{Normalisasi matriks}

Setiap elemen pada matriks D dinormalisasikan untuk mendapatkan matriks normalisasi R. Setiap normalisasi dari nilai rij dapat dilakukan dengan perhitungan sebagai berikut:

$$
\begin{aligned}
& \boldsymbol{r}_{\boldsymbol{i j}}=\frac{\boldsymbol{X}_{i j}}{\sqrt{\sum_{i=1}^{m} \boldsymbol{X}_{i j}^{2}}} \\
& \text { Untuk } \mathrm{i}=1,2,3, \ldots, \mathrm{m} \\
& \mathrm{j}=1,2,3, \ldots, \mathrm{n}
\end{aligned}
$$

2. Pembobotan pada matriks yang telah dinormalisasikan Diberikan bobot $\mathrm{W}=(\mathrm{w} 1, \mathrm{w} 2, \ldots, \mathrm{wn})$, sehingga weighted normalized matrix D dapat dihasilkan sebagai berikut:

$$
D=\left[\begin{array}{lll}
W_{1} r_{11} & W_{2} r_{12} \cdots & W_{n} r_{1 n} \\
W_{1} r_{21} & & \\
W_{1} r_{m 1} & W_{2} r_{m 2} \cdots & W_{n} r_{m n}
\end{array}\right]
$$

Menentukan solusi ideal positif dan solusi ideal negative Solusi ideal positif dinotasikan dengan $\mathrm{A}+$ dan solusi ideal negatife dinotasikan dengan A-, sebagi berikut :

\section{Menentukan Solusi Ideal (+) \& (-)}

$A+=\left\{(\max v i j \mid j \in J)\left(\min v i j \mid j \in J^{\prime}\right), i=1,2,3, \ldots m\right\}=\{v 1+$, $\mathrm{v} 2+, \ldots \mathrm{vm}+\}$

$A^{-}=\left\{(\max v i j \mid j \in J)\left(\min v i j \mid j \in J^{\prime}\right), i=1,2,3, \ldots m\right\}=\{v 1-$, $\mathrm{v} 2-, \ldots \mathrm{vm}-\}$

Dimana:

$\mathrm{vij}=$ elemen matriks $\mathrm{V}$ baris ke-i dan kolom ke- $\mathrm{j}$

$\mathrm{J}=\{\mathrm{j}=1,2,3, \ldots, \mathrm{n}$ dan $\mathrm{j}$ berhubung dengan benefit criteria $\}$

$\mathrm{J} '=\{\mathrm{j}=1,2,3, \ldots, \mathrm{n}$ dan $\mathrm{j}$ berhubung dengan cost criteria $\}$ Separation measure ini merupakan pengukuran jarak dari suatu alternatif ke solusi ideal positif dan solusi ideal negatif. Perhitungan matematisnya adalah sebagai berikut: Separation measure untuk

$$
\text { solusi } \quad \begin{aligned}
& \text { ideal } \\
& \left.S_{i}^{+}=\sqrt{\sum_{j=1}^{n}\left(V_{i j}\right.}+V_{i}^{+}\right) 2, \text { dengan } i=1,2,3, \ldots m
\end{aligned}
$$$$
\text { positif }
$$

Separation measure untuk solusi ideal negatif

$$
\left.S_{i}^{-}=\sqrt{\sum_{j=1}^{n}\left(V_{i j}\right.}-V_{i}^{-}\right) 2, \text { dengan } i=1,2,3, \ldots m
$$

4. Menghitung kedekatan relative dengan ideal positif Kedekatan relative dari alternatif A+ dengan solusi ideal Adirepresentasikan dengan:

$$
C_{i}=\frac{S_{i}^{-}}{S_{i}^{-}+S_{i}^{+}} \operatorname{dengan} 0<C_{i}<1 \mathrm{dan} i=1,2,3, \ldots, \mathrm{m}
$$

\section{Mengurutkan Pilihan}

Alternatif dapat dirangking berdasarkan urutan $C_{i}$. Maka dari itu, alternatif terbaik adalah salah satu yang berjarak terpendek terhadap solusi ideal dan berjarak terjauh dengan solusi ideal negatif.

\section{METODOLOGI PENELITIAN}

Metode yang dilakukan dalam penelitian ini adalah metode SMART digunakan untuk mencari nilai normalisasi matriks untuk setiap kriteria dan dilanjutkan dengan metode TOPSIS untuk pengurutan kualitas berdasarkan alternatif terbaik. Langkah-langkah yang digunakan dalam penelitian ini adalah sebagai berikut:

1. Menentukan kriteria pemlihan kualitas varietas padi. Kriteria terdiri dari umur tanaman, tinggi tanaman, kerontokan, rata-rata hasil dan potensi hasil

2. Menentukan bobot unuktuk masing-masing kriteria.

3. Normalisasi bobot

Menghitung normalisasi bobot dari setiap kriteria dengan membandingkan nilai bobot kriteria dengan jumlah bobot kriteria, menggunakan persamaan (2.2)

4. Menghitung nilai utility untuk setiap alternatif Menentukan nilai utility dengan mengkonversikan nilai kriteria pada masing-masing kriteria menjadi nilai kriteria data baku. Nilai utility ini tergantung pada sifat kriteria itu sendiri.

5. Proses pengurutan kualitas varietas padi Pengurutan kualitas varietas padi dilakukan menggunakan metode TOPSIS, setelah melakukan pembobotan menggunakan metode SMART, pengurutan dilakukan dengan terlebih dahulu melakukan perhitungan nilai utility untuk setiap alternatif. Menghitung nilai ideal positif dan ideal negatif, menentukan nilai preferensi untuk setiap alteranatif

\section{PEMBAHASAN DAN HASIL}

\section{Proses perhitungan bobot}

Memberikan bobot kriteria dengan nilai 1 s.d. 100 berdasarkan tingkat kepentingan kriteria. Nilai yang diberikan pada bobot 
kriteria ini berdasarkan pada penilaian pengambil keputusan, seperti yang disajikan dalam tabel 1

Tabel 1 Tabel bobot kriteria

\begin{tabular}{|l|l|l|}
\hline Kode & Krieria & Bobot \\
\hline C1 & Umur Tanaman & 80 \\
\hline C2 & Tinggi Tanaman & 75 \\
\hline C3 & Kerontokan & 70 \\
\hline C4 & Rata-rata hasil & 85 \\
\hline C5 & Potensi hasil & 65 \\
\hline
\end{tabular}

\section{Normalisasi bobot kriteria}

Normalisasi bobot kriteria dihitung berdasarkan persamaan (2.2) yaitu dengan membagi nilai masing-basing bobot dengan jumlah total nilai bobot

1. Menghitung bobot kriteria umur tanaman

$$
\frac{\text { bobot }}{\text { jumlah bobot }}=\frac{80}{375}=0,213
$$

2. Menghitung bobot kriteria tinggi tanaman

$$
\frac{\text { bobot }}{\text { jumlah bobot }}=\frac{75}{375}=0,2
$$

Dst....sampai dengan perhitungan kriteria rata-rata hasil. Hasil akhir prthitungan disajikan dalam tabel 2

Tabel 2 Tabel Normalisasi Bobot Kriteria

\begin{tabular}{|c|c|c|c|}
\hline Kode & Krieria & Bobot & $\begin{array}{c}\text { Normalisasi } \\
\text { bobot kriteria }\end{array}$ \\
\hline C1 & Umur Tanaman & 80 & 0,213 \\
\hline C2 & Tinggi Tanaman & 75 & 0,2 \\
\hline C3 & Kerontokan & 70 & 0,186 \\
\hline C4 & Rata-rata hasil & 85 & 0,226 \\
\hline C5 & Potensi hasil & 65 & 0,173 \\
\hline
\end{tabular}

\section{Menghitung Nilai Utility}

Menentukan nilai utility ini tergantung dari sifat masing-masing kriteria. Sifat atau tipe dari masing-masing kriteria dalam penelitian ini disajikan dalam tabel 3

Tabel 3 Tabel Utility Kriteria

\begin{tabular}{|c|c|c|}
\hline Kode & Krieria & Tipe kriteria \\
\hline C1 & Umur Tanaman & Benefit \\
\hline C2 & Tinggi Tanaman & Benefit \\
\hline C3 & Kerontokan & Benefit \\
\hline C4 & Rata-rata hasil & Benefit \\
\hline C5 & Potensi hasil & Benefit \\
\hline
\end{tabular}

Dari tabel 3 dapat dijelaskan tipe kriteria yang digunakan dalam penelitian ini adalah tipe kriteria benefit untuk semua kriteria, karena semakin besar nilai setiap kriteria makan akan semakin baik.

\section{Menghitung nilai Utility untuk setiap kriteria}

Tabel 4 Tabel Bobot setiap Alternatif

\begin{tabular}{|c|c|c|c|c|c|}
\hline Varietas & Umur & Tinggi & Kerontokan & $\begin{array}{c}\text { Rata } \\
\text { hasil }\end{array}$ & $\begin{array}{c}\text { Potensi } \\
\text { Hasil }\end{array}$ \\
\hline IR 36 & 20 & 40 & 50 & 50 & 20 \\
\hline Silugonggo & 80 & 100 & 50 & 50 & 20 \\
\hline Cibodas & 80 & 100 & 50 & 50 & 20 \\
\hline Digal & 80 & 60 & 50 & 25 & 20 \\
\hline Cimalaya & 80 & 80 & 75 & 50 & 20 \\
\hline tuket petuna & 80 & 100 & 25 & 25 & 20 \\
\hline Sunggal & 80 & 40 & 50 & 25 & 40 \\
\hline batang gadis & 60 & 100 & 50 & 50 & 40 \\
\hline Angke & 60 & 60 & 100 & 50 & 40 \\
\hline Cisadane & 100 & 100 & 50 & 25 & 20 \\
\hline Maro & 60 & 80 & 50 & 50 & 80 \\
\hline Rokan & 60 & 100 & 50 & 50 & 60 \\
\hline hipa 3 & 60 & 80 & 50 & 50 & 80 \\
\hline hipa 4 & 60 & 80 & 25 & 100 & 100 \\
\hline hipa 5 ceva & 80 & 100 & 25 & 75 & 60 \\
\hline hipa 6 jate & 80 & 100 & 50 & 75 & 100 \\
\hline hipa 7 & 60 & 60 & 50 & 75 & 100 \\
\hline hipa 8 & 60 & 100 & 50 & 75 & 100 \\
\hline
\end{tabular}

\section{Menghitung nilai utility setiap kriteria .}

Untuk menghitung nilai utility terlebih dahulu menentukan nilai Cmin dan Cmax dari setiap alternatif dan dimasukan kedalam persamaan 2.3

Tabel 5 Tabel Nilai Utility

\begin{tabular}{|c|c|c|c|c|c|}
\hline Alternatif & $\mathrm{C} 1$ & $\mathrm{C} 2$ & $\mathrm{C} 3$ & $\mathrm{C} 4$ & $\mathrm{C} 5$ \\
\hline $\mathrm{A} 1$ & 0 & 0 & 33,3 & 33,3 & 0 \\
\hline A2 & 75 & 100 & 33,3 & 33,3 & 0 \\
\hline A3 & 75 & 100 & 33,3 & 33,3 & 0 \\
\hline A4 & 75 & 66,6 & 33,3 & 0 & 0 \\
\hline A5 & 75 & 66,7 & 66,7 & 33,3 & 0 \\
\hline A6 & 75 & 100 & 0 & 0 & 0 \\
\hline A7 & 75 & 0 & 33,3 & 0 & 25 \\
\hline A8 & 50 & 100 & 33,3 & 33,3 & 25 \\
\hline A9 & 50 & 66,6 & 100 & 33,3 & 25 \\
\hline A10 & 100 & 100 & 33,3 & 0 & 0 \\
\hline A11 & 50 & 66,7 & 33,3 & 33,3 & 75 \\
\hline A12 & 50 & 100 & 33,3 & 33,3 & 50 \\
\hline A13 & 50 & 66,7 & 33,3 & 33,3 & 75 \\
\hline A14 & 50 & 66,7 & 0 & 100 & 100 \\
\hline A15 & 75 & 100 & 0 & 66,7 & 50 \\
\hline A16 & 75 & 100 & 33,3 & 66,7 & 100 \\
\hline A17 & 50 & 66,6 & 33,3 & 66,7 & 100 \\
\hline A18 & 50 & 100 & 33,3 & 66,7 & 100 \\
\hline
\end{tabular}

Keterangan
1. $\mathbf{C}_{1}:$ Umur tanaman
2. $\mathbf{C}_{2}$ : Tinggi tanaman
3. $\mathbf{C}_{3}$ : Kerontokan
4. $\mathbf{C}_{\mathbf{4}}$ : Rata-rata hasil
5. $\mathbf{C}_{5}$ : Potensi hasi 
Proses pengurutan hasil menggunakan metode TOPSIS

Tabel 6 Tabel Normalisasi Matriks Keputusan

\begin{tabular}{|c|c|c|c|c|c|}
\hline Alternatif & C1 & C2 & C3 & C4 & C5 \\
\hline A1 & 0 & 0 & 33,3 & 33,3 & 0 \\
\hline A2 & 75 & 100 & 33,3 & 33,3 & 0 \\
\hline A3 & 75 & 100 & 33,3 & 33,3 & 0 \\
\hline A4 & 75 & 66,6 & 33,3 & 0 & 0 \\
\hline A5 & 75 & 66,7 & 66,7 & 33,3 & 0 \\
\hline A6 & 75 & 100 & 0 & 0 & 0 \\
\hline A7 & 75 & 0 & 33,3 & 0 & 25 \\
\hline A8 & 50 & 100 & 33,3 & 33,3 & 25 \\
\hline A9 & 50 & 66,6 & 100 & 33,3 & 25 \\
\hline A10 & 100 & 100 & 33,3 & 0 & 0 \\
\hline A11 & 50 & 66,7 & 33,3 & 33,3 & 75 \\
\hline A12 & 50 & 100 & 33,3 & 33,3 & 50 \\
\hline A13 & 50 & 66,7 & 33,3 & 33,3 & 75 \\
\hline A14 & 50 & 66,7 & 0 & 100 & 100 \\
\hline A15 & 75 & 100 & 0 & 66,7 & 50 \\
\hline A16 & 75 & 100 & 33,3 & 66,7 & 100 \\
\hline A17 & 50 & 66,6 & 33,3 & 66,7 & 100 \\
\hline A18 & 50 & 100 & 33,3 & 66,7 & 100 \\
\hline Jumlah & 33,17 & 1366,6 & 599,6 & 666,5 & 725 \\
\hline
\end{tabular}

Pada tabel 6 berisi hasil dari perhitungan normalisasi setiap alternatif dihitung dengan terlebih dahulu menentukan nilai terbesar (max) dan nilai terkecil dari bobot setiap alternatif, selanjutnya setiap alternatif dari masing-masing kriteria dijumlahkan. Setelah selesai perhitungan normalisasi setiap alternatif dihitung akar dari jumlah setiap kriteria, seperti disajikan dalam tabel 7

Tabel 7 Tabel Hasil Akar Nilai Normalisai Matriks

\begin{tabular}{|c|c|c|c|c|}
\hline $\mathrm{C} 1$ & $\mathrm{C} 2$ & $\mathrm{C} 3$ & $\mathrm{C} 4$ & $\mathrm{C} 5$ \\
\hline 33,17 & 36,97 & 24,49 & 25,82 & 26,93 \\
\hline
\end{tabular}

Tahap selanjutnya adalah dengan membagi hasil akar nilai normalisasi matriks dengan nilai normalisasi matriks

Tabel 8 Tabel Hasil pembagian nilai normalisasi matriks

\begin{tabular}{|c|c|c|c|c|c|}
\hline Alternatif & C1 & C2 & C3 & C4 & C5 \\
\hline A1 & 0 & 0 & 1,36 & 1,29 & 0 \\
\hline A2 & 2,26 & 2,71 & 1,36 & 1,29 & 0 \\
\hline A3 & 2,26 & 2,71 & 1,36 & 1,29 & 0 \\
\hline A4 & 2,26 & 1,80 & 1,36 & 0,00 & 0 \\
\hline A5 & 2,26 & 1,80 & 2,72 & 1,29 & 0 \\
\hline A6 & 2,26 & 2,71 & 0 & 0 & 0 \\
\hline A7 & 2,26 & 0 & 1,36 & 0,00 & 0,93 \\
\hline A8 & 1,51 & 2,71 & 1,36 & 1,29 & 0,93 \\
\hline A9 & 1,51 & 1,80 & 4,08 & 1,29 & 0,93 \\
\hline A10 & 3,02 & 2,71 & 1,36 & 0 & 0 \\
\hline A11 & 0,66 & 1,80 & 1,36 & 1,29 & 2,79 \\
\hline A12 & 1,51 & 2,71 & 1,36 & 1,29 & 1,86 \\
\hline A13 & 1,51 & 1,80 & 1,36 & 1,29 & 2,79 \\
\hline A14 & 1,51 & 1,80 & 0 & 3,87 & 3,71 \\
\hline
\end{tabular}

DOI: https://doi.org/10.30743/infotekjar.v3i2.1018

\begin{tabular}{|c|c|c|c|c|c|}
\hline A15 & 2,26 & 2,71 & 0 & 2,58 & 1,86 \\
\hline A16 & 2,26 & 2,71 & 1,36 & 2,58 & 3,71 \\
\hline A17 & 1,51 & 1,80 & 1,36 & 2,58 & 3,71 \\
\hline A18 & 1,51 & 2,71 & 0,90 & 2,58 & 3,71 \\
\hline
\end{tabular}

Normalisasi terbobot yaitu Data Normalisasi * Bobot, dimana data hasil Normalisasi R dikalikan Bobot kriteria maka akan menghasilkan Normalisasi Terbobot.

Tabel 9 Tabel Normalisasi Bobot

\begin{tabular}{|c|c|c|c|}
\hline Kode & Krieria & Bobot & Normalisasi bobot \\
\hline C1 & Umur Tanaman & 80 & 0,8 \\
\hline C2 & Tinggi Tanaman & 75 & 75 \\
\hline C3 & Kerontokan & 70 & 0,7 \\
\hline C4 & Rata-rata hasil & 85 & 0,85 \\
\hline C5 & Potensi hasil & 65 & 0,65 \\
\hline
\end{tabular}

Selanjutnya nilai normalisasi bobot dikalikan dengan nilai hasil pembagian normalsasi matriks, hasilnya akan terlihat pada tabel 10

Tabel 10 Tabel Hasil Normalisasi Pembobotan

\begin{tabular}{|c|c|c|c|c|c|}
\hline & C1 & C2 & C3 & C4 & C5 \\
\hline A1 & 0 & 0 & 0,951944 & 1,096385 & 0 \\
\hline A2 & 1,809068067 & 2,028806 & 0,951944 & 1,096385 & 0 \\
\hline A3 & 1,809068067 & 2,028806 & 0,951944 & 1,096385 & 0 \\
\hline A4 & 1,809068067 & 1,351185 & 0,951944 & 0 & 0 \\
\hline A5 & 1,809068067 & 1,353214 & 1,906747 & 1,096385 & 0 \\
\hline A6 & 1,809068067 & 2,028806 & 0 & 0 & 0 \\
\hline A7 & 1,809068067 & 0 & 0,951944 & 0 & 0,60351 \\
\hline A8 & 1,206045378 & 2,028806 & 0,951944 & 1,096385 & 0,60351 \\
\hline A9 & 1,206045378 & 1,351185 & 2,858691 & 1,096385 & 0,60351 \\
\hline A10 & 8,8 & 2,028806 & 0,951944 & 0 & 0 \\
\hline A11 & 0,530659966 & 1,353214 & 0,951944 & 1,096385 & 1,81053 \\
\hline A12 & 1,206045378 & 2,028806 & 0,951944 & 1,096385 & 1,20702 \\
\hline A13 & 1,206045378 & 1,353214 & 0,951944 & 1,096385 & 1,81053 \\
\hline A14 & 1,206045378 & 1,353214 & 0 & 3,292447 & 2,414039 \\
\hline A15 & 1,809068067 & 2,028806 & 0 & 1,025967 & 1,20702 \\
\hline A16 & 1,809068067 & 2,028806 & 0,951944 & 2,196062 & 2,414039 \\
\hline A17 & 1,206045378 & 1,351185 & 0,951944 & 2,196062 & 2,414039 \\
\hline A18 & 1,206045378 & 2,028806 & 0,630553 & 2,196062 & 2,414039 \\
\hline & & & & &
\end{tabular}

\section{Menentukan matriks solusi ideal positif dan ideal negatif}

Matriks solusi ideal positif dan negative

$\mathrm{A}+=$ nilai $\max$ dari hasil nilai kriteria terbobot $(\max =$ nilai terbesar)

$\mathrm{A}-=$ nilai $\min$ dari hasil nilai kriteria terbobot $(\mathrm{min}=$ nilai terkecil $)$

Tabel 11 Tabel Matriks Solusi Ideal Positif dan Negatif

\begin{tabular}{|c|c|c|c|c|}
\hline Kriteria & POSITIF & A+ & NEGATIF & A- \\
\hline Umur Tanaman & $\mathrm{Y}+$ & 8,8 & $\mathrm{Y}-$ & 0 \\
\hline Tinggi Tanaman & $\mathrm{Y}+$ & 2,02880 & $\mathrm{Y}-$ & 0 \\
\hline Kerontokan & $\mathrm{Y}+$ & 2,85869 & $\mathrm{Y}-$ & 0 \\
\hline Rata-rata Hasil & $\mathrm{Y}+$ & 2,85869 & $\mathrm{Y}-$ & 0 \\
\hline Potensi Hasil & $\mathrm{Y}+$ & 2,41403 & $\mathrm{Y}-$ & 0 \\
\hline
\end{tabular}




\begin{tabular}{|c|c|c|c|c|c|}
\hline $\mathrm{A}+$ & 8,8 & 2,028806 & 2,858691 & 2,858691 & 2,414039 \\
\hline $\mathrm{A}-$ & 0 & 0 & 0 & 0 & 0 \\
\hline
\end{tabular}

Alternatif :

IR 36

$\mathrm{A}+=(8,8-0 * 2)+(2,028806-0 * 2)+(2,858691-0,951944 * 2)+$ $(2,858691-1,096385 * 2)+(1,0963850 * 2)=\mathbf{1 4 , 8 6 3 5 6 9 4 9}$

$\mathrm{A}-=(0-0 * 2)+(0-0 * 2)+(0-0,951944 * 2)+(0-1,096385 * 2)+(0-$ $0 * 2)=-4,09666$

\section{Silugonggo}

$\mathrm{A}+=(8,8-1,809068067 * 2)+(2,028806-, 028806 * 2)+($ $2,858691-0,951944 * 2)+(2,858691-1,096385 * 2)+(2,414039-0 * 2)$ $=-\mathbf{4 2 , 8 1 2 1 7 8 9 7}$

A- $=(0-1,809068067 * 2)+(0-, 028806 * 2)+(0-0,951944 * 2)$

$+(0-1,096385 * 2)+(0-0 * 2)=\mathbf{7 , 1 8 7 8 2 1}$

Dst....sampai perhitngan alternatif terakhir

Dari hasil perhitungan disajikan pada tabel 12

Tabel 12 Tabel Hasil Matriks Ideal Positif dan Negatif

\begin{tabular}{|c|c|c|}
\hline Jarak alternatif & Positif & Negatif \\
\hline IR 36 & 14,86356949 & $-4,09666$ \\
\hline Silugonggo & $-42,81217897$ & 7,187821 \\
\hline Cibodas & 7,187821027 & 7,187821 \\
\hline Digal & 10,73583353 & 10,73583 \\
\hline Cimalaya & 6,629400283 & 6,6294 \\
\hline Tuket petuna & 11,28447928 & 11,28448 \\
\hline Sunggal & 12,23118364 & 12,23118 \\
\hline Batang gadis & 7,186846707 & 7,186847 \\
\hline Angke & 4,72859531 & 4,728595 \\
\hline Cisadane & $-4,601272852$ & $-4,60127$ \\
\hline Maro & 12,6337779 & 7,474763 \\
\hline Rokan & 5,979827009 & 5,979827 \\
\hline Hipa 3 & 5,520482365 & 6,123992 \\
\hline Hipa 4 & $-66,74318529$ & 2,428736 \\
\hline Hipa 5 ceva & 6,818506395 & 6,818506 \\
\hline Hipa 6 jate & 0,160387354 & 0,160387 \\
\hline Hipa 7 & 2,721675248 & 2,721675 \\
\hline Hipa 8 & 2,009215087 & 2,009215 \\
\hline & & \\
\hline & & \\
\hline
\end{tabular}

Menghitung jarak alternatif dengan cara : jarak alternatif positif + jarak alternatif negatif.

Tabel 13 Tabel Jarak Alternatif

\begin{tabular}{|c|c|c|c|}
\hline $\begin{array}{c}\text { Jarak } \\
\text { alternatif }\end{array}$ & Positif & Negatif & $\begin{array}{c}\text { D++D } \\
\text { (Positif+Negatif) }\end{array}$ \\
\hline IR 36 & 14,86356949 & $-4,09666$ & 10,76691 \\
\hline Silugonggo & $-42,81217897$ & 7,187821 & $-35,6244$ \\
\hline Cibodas & 7,187821027 & 7,187821 & 14,37564 \\
\hline Digal & 10,73583353 & 10,73583 & 21,47167 \\
\hline Cimalaya & 6,629400283 & 6,6294 & 13,2588 \\
\hline Tuket petuna & 11,28447928 & 11,28448 & 22,56896 \\
\hline Sungga & 12,231183 & & 24,46237 \\
\hline
\end{tabular}

218 Fatma Sari Hutagalung

\begin{tabular}{|c|l|l|l|}
\hline Batang gadis & 7,186846707 & 7,186847 & 14,37369 \\
\hline Angke & 4,72859531 & 4,728595 & 9,457191 \\
\hline Cisadane & $-4,601272852$ & $-4,60127$ & $-9,20255$ \\
\hline Maro & 12,6337779 & 7,474763 & 20,10854 \\
\hline Rokan & 5,979827009 & 5,979827 & 11,95965 \\
\hline Hipa 3 & 5,520482365 & 6,123992 & 11,64447 \\
\hline Hipa 4 & $-66,74318529$ & 2,428736 & $-64,3144$ \\
\hline Hipa 5 ceva & 6,818506395 & 6,818506 & 13,63701 \\
\hline Hipa 6 jate & 0,160387354 & 0,160387 & 0,320775 \\
\hline Hipa 7 & 2,721675248 & 2,721675 & 5,44335 \\
\hline Hipa 8 & 2,009215087 & 2,009215 & 4,01843 \\
\hline
\end{tabular}

Tabel 33 berisi hasil perhitungan nilai prefrensi untuk setiap alternatif dengan cara menjumlahkan nilai ideal positif dan ideal negatif.

\section{Pengurutan kualitas varietas padi}

Proses pengurutan kualitas padi dengan cara mengurutkan nilai terendah sampai terbesar

Tabel 13 Tabel Pengurutan Varietas Padi

\begin{tabular}{|c|c|c|}
\hline Jarak alternatif & D++D & Rangking \\
\hline IR 36 & 10,76691 & 5 \\
\hline Silugonggo & $-35,6244$ & 17 \\
\hline Cibodas & 14,37564 & 11 \\
\hline Digal & 21,47167 & 13 \\
\hline Cimalaya & 13,2588 & 9 \\
\hline Tuket petuna & 22,56896 & 14 \\
\hline Sunggal & 24,46237 & 15 \\
\hline Batang gadis & 14,37369 & 10 \\
\hline Angke & 9,457191 & 4 \\
\hline Cisadane & $-9,20255$ & 16 \\
\hline Maro & 20,10854 & 12 \\
\hline Rokan & 11,95965 & 6 \\
\hline Hipa 3 & 11,64447 & 7 \\
\hline Hipa 4 & $-64,3144$ & 18 \\
\hline Hipa 5 ceva & 13,63701 & 8 \\
\hline Hipa 6 jate & 0,320775 & 1 \\
\hline Hipa 7 & 5,44335 & 3 \\
\hline Hipa 8 & 4,01843 & 2 \\
\hline & & \\
\hline
\end{tabular}

\section{KESIMPULAN DAN SARAN}

\section{Kesimpuan}

Berdasarkan penelitian dan pembahasan sebelumnya, maka diambil kesimpulan :

1. Indikator penting dalam menentukan kualitas varietas padi adalah umur tanaman dan rata-rata hasil.

2. Hasil dari penggabungan metode SMART dan TOPSIS memperoleh hasil yang akurat dan lebih objektif dibandingkan dengan hasil peneliti sebelumnya yang hanya menggunakan satu metode saja yakni metode TOPSIS, karena hanya dengan menggunakan metode TOPSIS bobot yang diberikan apada setiap alternatif tidak dilakukan normalisasi, sedangkan bila dikombinasikan dengan metode SMART, bobot akan

DOI: https://doi.org/10.30743/infotekjar.v3i2.1018 
dinormalisasikan sebelum dilakuakan pehitungan matriks.

3. Hasil dari penelitian ini memperoleh varietas padi yang berkualitas :

Super : Hipa 6 jate, Hipa 5 ceva, Hipa 7, Hipa 8, Angke, dan Cisadane

premium : Batang gadis, IR 36, Hipa 4, Sunggal, Silugonggo, dan Hipa 3

Rendah : Tuket petuna, Digal , Cibodas, Cimalaya, Rokan dan Maro

\section{Saran}

Kriteria yang digunakan dalam penelitian hanya umur tanaman, tinggi tanaman, kerontokan, rata-rata hasil dan potensi hasil, penulis berharap ada kriteria yang lebih agar hasil semakit kuat dan baik. Penelitian ini menggabungkan metode SMART dan TOPSIS penulis mengharapkan adanya menggabungan metode lain untuk menyelesaikan masalah dan menggunakan varietas padi yang lebih banyak. .

\section{REFERENSI}

[1] Asnur, Sarah, 2018, September, 5, Interview jenis varietas padi dan kriteria-kriteria yang digunakan dalam pemilihan kualitas varietas padi

[2] Arbelia and Paryanta, "Penerapan Metode AHP dan TOPSIS sebagai Sistem Pendukung Keputusan dalam Menentukan Kenaikan Jabatan bagi Karyawan”, Jurnal Ilmiah Infotech. Vol 20., pp. 9-17, Juni 2014.

[3] Bray, Robert. 2015. Developing a participative multi criteria decision making technique:a case study. International Journal of Management and Decision Making.

[4] Jamilah, Muyasir, Syakur, "PERTUMBUHAN DAN HASIL PADI (Oryza sativa L.)AKIBAT PEMBERIAN ARANG AKTIF DAN UREA Growth and Yield of RiceWith Charcoal and Urea, Banda Aceh, Juli 2012

[5] Kusumadewi,S., Hartati,S.,Harjoko,A.,Wardoyo,R., 2006, Fuzzy Mulri Attribut Decission Making (FUZZY MADM), Penerbit : Garaha Ilmu, Yogyakarta

[6] Kusumadewi, 2007, "Sistem Pendukung Keputusan Dengan Metode TOPSIS ", Penerbit : Rindy , Graha Ilmu, Yogyakarta

[7] Kusrini, 2007, Konsep dan Aplikasi Sistem Pendukung Keputusan, Penerbit Andi, Yogyakarta.

[8] Monavvarian, A, Fathi, MR, Zarchi, MK \& Faghih, A, 2011, Combining ANP with TOPSIS in selecting Knowledge Management Strategies (Case Study: Pars Tire Company), European Journal of Scientific Research, pp. 538-546.

[9] Olson, D.L., 1996. SMART. In: Decision Aids for Selection Problems. Springer Series in Operations Research. Springer, New York, NY.
[10] R Moh, Muhammad Tanzil, Achmad A, 2018, Sistem Pendukung Keputusan Pemilihan Varietas Unggul Jagung Hibrida Menggunakan Metode AHP-SMART. Jurnal Pengembangan Teknologi Informasi dan Ilmu Komputer . Program Studi Teknik Informatika, Fakultas Ilmu Komputer, Universitas Brawijaya pp : 3373-3380

[11] Raja tama , 2018 , PENENTUAN BENIH PADI TERBAIK UNTUK MENINGKATKAN HASIL PANEN MENGGUNAKAN METODE FUZZY MULTI CRITERIA DECISION MAKING. Jurnal matik penusa Volume 22, No. 1, pp : 23-28

[12] Turban, E, Aronson, EJ \& Liang, T, 2005, Decision Support Systems and Intelligent System (7th edition), Prentice Hall Publication. 